\title{
Cigarette smoking and lung function decline beyond quitting
}

\author{
Jennifer L. Perret ${ }^{1,2,3} \wedge$, E. Haydn Walters ${ }^{1}$ \\ ${ }^{1}$ Allergy and Lung Health Unit, Melbourne School of Population and Global Health, The University of Melbourne, Victoria, Australia; ${ }^{2}$ Department \\ of Respiratory and Sleep Medicine, Austin Hospital, Melbourne, Australia; ${ }^{3}$ Institute for Breathing and Sleep (IBAS), Melbourne, Australia \\ Correspondence to: Dr. Jennifer L. Perret. Level 3, 207 Bouverie Street, The University of Melbourne, Victoria 3010, Australia. \\ Email: jennifer.perret@unimelb.edu.au. \\ Comment on: Oelsner EC, Balte PP, Bhatt SP, et al. Lung function decline in former smokers and low-intensity current smokers: a secondary data \\ analysis of the NHLBI Pooled Cohorts Study. Lancet Respir Med 2020;8:34-44.
}

Submitted May 01, 2020. Accepted for publication May 22, 2020.

doi: $10.21037 / \mathrm{atm}-20-3667$

View this article at: http://dx.doi.org/10.21037/atm-20-3667

\section{The tobacco epidemic}

From a public health perspective, the global epidemic of tobacco smoking is one of the most prominent features of the $20^{\text {th }}$ Century. In the U.S., at the time of the 1964 Surgeon General's report on smoking and health, the rise of population cigarette consumption peaked at more than 4,000 cigarettes per year per capita (1). The subsequent decline can be attributed to a combination of multiple tobacco control measures that were sustained over timefrom advertising and sponsorship bans, focused federal taxes, clean indoor air laws, nicotine replacement therapies and other anti-smoking campaigns targeting the smoking general public (1). Smoking rates for U.S. adults fell 3-fold over this 50 -year period-from $42.4 \%$ in 1965 to $14.0 \%$ in 2017 (2) —such that former or ex-smokers by then now outnumbered smokers in the general communities of most high-income countries.

Despite this decline in tobacco's popularity, smokingrelated lung diseases such as chronic obstructive pulmonary disease (COPD) and lung cancer continued to appear due to a latent phase of decades (3). A recent analysis of the Global Burden of Disease Study (GBD 1992-2017) data interestingly showed the relative risk of COPD mortality continued to increase in the U.S., and although this has been attributed to the smoking peak (4), increasing urbanisation with its pollution risks almost certainly played a role. China now has the largest number of active smokers in the world with a prevalence peaking around $34.1 \%$ in 1996, though that represented $63 \%$ of men and only $3.8 \%$ of women (5), which in 2014-2015, was still 58\% and 4.0\% respectively (6). Nonetheless, the relative risk of COPD mortality has been reported as decreasing in China over this period (4), with this paradox attributed to public health measures that have achieved lower indoor and outdoor air pollution targets through cleaner energy sources in spite of industrialization and increased motor vehicle traffic (7). Even so, as for any country, reducing tobacco consumption would be the most effective means of preventing COPD and other smoking-related diseases. Through the direction of the World Health Organization, tobacco control measures have been at least partially introduced into many developing countries, covering about 5 billion $(65 \%$ of people) worldwide (8).

\section{The 1977 landmark study of smokers}

It is now over 40 years since Fletcher and Peto described their view of the natural history of COPD (9) which formed the foundation of how health and public health professionals approach COPD prevention through promoting smoking abstinence and quitting. It describes the decline in lung function in terms of the forced expiratory volume in one second $\left(\mathrm{FEV}_{1}\right)$ which has been traditionally used to follow the progression of COPD, although this is only

^ ORCID: 0000-0001-7034-0615. 


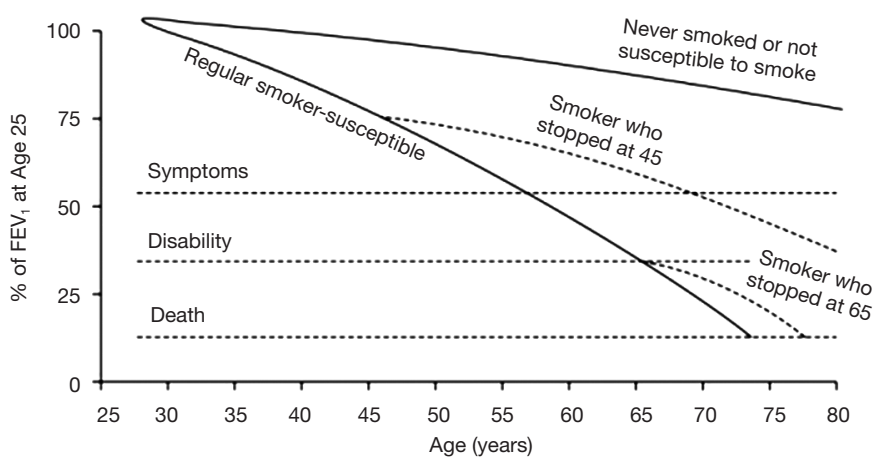

Figure 1 Schema of the observed lung function of working men of West London. Adapted by permission from BMJ Publishing Group Limited [Fletcher C and Peto R. The natural history of chronic airflow obstruction. Br Med J 1977;1(6077):1645-1648] (9,10).

one measure of lung function. By observing the smoking habits and $\mathrm{FEV}_{1}$ of 792 English men followed at 6-monthly intervals for 8 years, but at differing ages, the concept of the susceptible smoker and adverse $\mathrm{FEV}_{1}$ trajectories was founded. In other words, they proposed that only a subset of smokers is at risk of the lung function damage that typically progresses to severe COPD (see Figure 1). A key message was that the trajectory/slope of $\mathrm{FEV}_{1}$ decline for these susceptible smokers could "revert back to normal" if they quit the habit (9). Thus, susceptible individuals who quit smoking by mid-adult life could delay the onset of disabling breathlessness by several years, while quitting later, even around the retirement age, could still result in a modest survival benefit. A second realisation was that young adult smokers often cut down or ended their tobacco consumption due to respiratory symptoms, such that these most severely affected individuals would be then classified among the lighter or ex-smokers respectively. Despite the importance of this work (9), it has encouraged health care professionals, guideline and funding bodies to overlook the potential for ongoing lung function loss in this susceptible subgroup, who took up the additive habit when peer group pressures and the media dominated over the weak public health messages of the era.

\section{The rationale for the present study}

Oelsner and colleagues have extended this work by comprehensively undertaking a secondary analysis of the lung function data of the National Heart Lung and Blood Institute (NHLBI) Pooled Cohorts Study to more definitively establish the relationship between cigarette smoking and lung function decline in the modern era (11).
The study rationale was based on perceived inconsistencies in the literature. Firstly, in the only randomized controlled trial of smoking cessation, Anthonisen and colleagues documented an improvement in the lung function measure, $\mathrm{FEV}_{1}$, for two years after sustained quitting which then declined at a lesser rate than that of continuing smokers (12). This finding was unexpected and suggested a sizeable proportion had the so-called asthma-COPD overlap (13). Among survivors, the $\mathrm{FEV}_{1}$ then declined at $28 \mathrm{~mL} / \mathrm{year}$ for sustained quitters, $48 \mathrm{~mL} /$ year for intermittent quitters, and $62 \mathrm{~mL} /$ year for continuing smokers (14), but due to the exclusion of never-smokers, these rates of decline were not compared with "normal" ageing.

Secondly, pathological evidence suggests that airway cellular and remodelling changes of COPD persist beyond smoking cessation, as distinct from any lung tissue destruction known as emphysema. Of many studies, the work by Hogg and colleagues (15) described increasing mucus and inflammatory cells across the spectrum of COPD severity, including B-cell containing lymphoid follicles that suggest microbial colonization and/or infection as a driver for those susceptible. Smoking itself is associated with increased cytotoxic CD8+ cells in the small airways which is the main site of obstruction in COPD $(15,16)$, but combined with reduced total cell counts, reduced neutrophil and increased macrophage numbers in larger conducting airways, this may represent smoking-related inflammatory and immunosuppressive processes, as well as airway remodelling in smokers with COPD (16). However, interpreting histopathological studies is limited by their cross-sectional nature, which almost invariably cannot investigate the link between lung function changes and airway wall inflammation over time. 
Thirdly, and most obviously, the work by Oelsner and colleagues seemed to have been prompted by the 2010 meta-analysis by Lee and colleagues that did not find differences in the rate of $\mathrm{FEV}_{1}$ decline between never, past smokers and recent quitters (17). But this meta-analysis was limited by including studies of cross-sectional design and those measuring spirometry prior to internationally accepted technical standards. But in identifying a knowledge gap, Lee and colleagues described an "ideal" study which would include a number of large studies that recorded: smoking habits, $\mathrm{FEV}_{1}$ levels and confounding variables at regular intervals so as to assess the lung function decline trajectory between at least two timepoints, and separately for continuing smokers and quitters using prospective and recently recorded smoking data (17).

\section{The present study}

Oelsner and colleagues have responded by performing a secondary analysis of the NHLBI Pooled Cohorts Study to document trajectories of cigarette smokingrelated $\mathrm{FEV}_{1}$ decline over a median 7 -year period (IQR: 3, 20) (11). This consortium comprises multiple general population-based U.S. cohorts with harmonized respiratory data that included pre-bronchodilator (but not post-bronchodilator) spirometry measured in accordance with the 2005 American Thoracic Society/European Respiratory Society standards (18). Six of these cohorts were included in the present analysis. The 25,352 eligible participants who had lung function measured at $\geq 2$ timepoints (39\% of 65,251 in total) were adults of all ages but with a median birth year in the 1930s, corresponding with the expansion phase of the smoking epidemic. Approximately two-thirds (60-68\%) had a pre-bronchodilator $\mathrm{FEV}_{1}$ decline calculated from two measurements with trajectories ( $\geq 3$ timepoints) developed for the remainder. Smoking categories were based on self-reported smoking status and daily intensity, namely: consistent never smokers, consistent ex-smokers, consistent current smokers and variable smokers that included those who had quit. Linear mixed models with cohort specific unstructured covariance matrices, adjusted for confounders, accommodated the repeated $\mathrm{FEV}_{1}$ measures and age variation. An additional sensitivity analysis excluded "prevalent lung disease" defined by pre-BD lung function less than lower limits of normal, self-reported doctordiagnosed respiratory conditions and self-reported inhaler use.
While associations between spectrum of cigarette smoking exposures and $\mathrm{FEV}_{1}$ decline were reported, the paper focused on the associations for recency of smoking (decade since quit date), low smoking intensity ( $<5$ cigarettes/day) and low cumulative consumption (1-10 pack-years). In this paragraph, the excess in lung function loss compared with never smokers has been reported, for whom the unadjusted mean $\mathrm{FEV}_{1}$ decline was $31 \mathrm{~mL} / y e a r$. A most striking feature was a "gradient of harm" for more recent decades since quitting smoking, but also a novel absolute excess of $\mathrm{FEV}_{1}$ decline even for those who had quit even over 30 years ago. Within the category of current smoking, the rate of excess $\mathrm{FEV}_{1}$ decline for those smoking $\leq 5$ cigarettes/day was almost nine times higher than the modest estimate for former and/or current smokers with a 1-10 pack-year smoking history [7.65 mL/ year (95\% CI: 6.21-9.09) versus 0.87 (0.17-1.57)], implying that current smoking per se was more important. The doseresponse relationship for smoking intensity was much less pronounced. The predicted $\mathrm{FEV}_{1}$ curves nicely illustrated these dose-response relationships (figure 2, panels B and $D$ respectively), but interestingly, the trajectories for increasing pack-year history was almost parallel with neversmokers (panel C), with a possible contribution from a transient improvement in recent ex-smokers (12), especially as only pre-bronchodilator spirometry was measured. When restricting the analysis to participants without co-existent lung disease, the magnitude of estimates reduced only slightly. The tables in the main document did not feature the $10.3 \%$ of participants who had quit during the period of interest, but importantly, the adjusted difference in excess $\mathrm{FEV}_{1}$ decline of $3.00 \mathrm{~mL} /$ year (95\% CI: 2.29-3.71) fell nicely between the estimates for longer-term quitters and current smokers (panel A, table S4).

The many strengths of this study have been outlined in Table 1, while some limitations are worth mentioning. Firstly, the possibility of residual confounding by socioeconomic status (SES) beyond adjustment for educational level is not excluded. Lower SES is associated with increased smoking rates (20), some jobs with hazardous occupational exposures, and lower levels of outdoor air pollution from residing in less urbanised areas (21). While all these factors need not be adjusted for separately, ideally the models would have included another SES variable such as the zip/postcode or state of testing.

Secondly, the estimate sizes were quite small in some instances and the definition of clinical significance provided by the authors seemed rather liberal. Thus, a cut-off of 
Table 1 Perceived strengths and weaknesses of the study by Oelsner and colleagues 2020

\begin{tabular}{|c|c|c|}
\hline Study component & Strengths & Weaknesses \\
\hline Methods & $\begin{array}{l}\text { Sensitivity analysis excluded individuals with clinical and/or } \\
\text { spirometrically-defined lung disease }\end{array}$ & $\begin{array}{l}\text { Only pre-bronchodilator } \mathrm{FEV}_{1} \text { decline reported (not } \\
\text { post-bronchodilator or } \mathrm{FEV}_{1} / \mathrm{FVC} \text { ratio) }\end{array}$ \\
\hline Findings & $\begin{array}{l}\text { Predicted } \mathrm{FEV}_{1} \text { curves with interactions by age to minimize } \\
\text { age-related confounding }\end{array}$ & $\begin{array}{l}\text { Not stratified by sex. Smoking categories consistently } \\
\text { reported as never, former and current smoking status } \\
\text { but underplayed the scenario of quitting during the } \\
\text { follow-up period }(10.3 \% \text {, table S4) }\end{array}$ \\
\hline Interpretation & $\begin{array}{l}\text { Dose-response associations strengthen causal inference, } \\
\text { especially for increasing years since quit date }\end{array}$ & $\begin{array}{l}\text { Small statistically significant effect size was not within } \\
\text { the measurement error of testing (19) }\end{array}$ \\
\hline Discussion & $\begin{array}{l}\text { Differences with the recent meta-analysis were } \\
\text { comprehensively discussed in terms of survivor bias; } \\
\text { healthy smoker effect; possible self-selection by smokers }\end{array}$ & $\begin{array}{l}\text { Possible self-selection of symptomatic individuals } \\
\text { (baseline } \mathrm{FEV}_{1} \text { decline of } 31 \mathrm{~mL} / \text { year seems relatively } \\
\text { high) }\end{array}$ \\
\hline $\begin{array}{l}\text { Strengths and } \\
\text { limitations }\end{array}$ & $\begin{array}{l}\text { Potential study weaknesses and differences with the recent } \\
\text { meta-analysis were comprehensively discussed }\end{array}$ & $\begin{array}{l}\text { Did not consider other potential confounders of } \\
\text { smoking-FEV } \text { decline relationship [see main text } \\
(20,21) \text { ] }\end{array}$ \\
\hline Conclusions & Strengthens the strong anti-smoking message & $\begin{array}{l}\text { The findings promote the traditional view of COPD } \\
\text { being only a "smokers' disease" which might } \\
\text { encourage complacency to not look for other } \\
\text { potentially modifiable risk factors such as asthma, } \\
\text { occupational exposures and air pollution }\end{array}$ \\
\hline
\end{tabular}

cigs/day, cigarettes per day; $\mathrm{FEV}_{1}$, forced expiratory volume in 1 second; IQR, interquartile range; SES, socioeconomic status.

$1.55 \mathrm{~mL} /$ year is small given the uncertainty around the measurement error of the test and the minimal clinically important difference (MCID) of $\geq 100 \mathrm{~mL}$ (19). But the dose-response nature of the findings does strengthen the biological plausibility of these causal associations.

Thirdly, a sensitivity analysis restricted to around 30 $40 \%$ of eligible participants who had trajectories derived from $\geq 3 \mathrm{FEV}_{1}$ measurements would have strengthened the study findings. Also, the ratio between $\mathrm{FEV}_{1}$ and forced vital capacity is more specific for airway obstruction.

\section{The study's importance in the field}

Despite some limitations, this paper (11) provides the best evidence that "former and low-intensity current smokers have excess lung function decline compared with never smokers". It describes an overall excess decline in a general population that spanned younger to older-aged adults, but regardless of time period or age group. It is timely because ex-smokers now commonly outnumber current smokers in many high-income countries following years of effective public health policy. The large participant numbers in part explain the narrow $95 \%$ confidence intervals, but perhaps the relatively short follow-up period for many has obscured the substantial variation in $\mathrm{FEV}_{1}$ decline expected for those with and without susceptibility to the harmful lung function effects of smoking.

Arguably, the most impressive finding was the inverse dose-response smoking- $\mathrm{FEV}_{1}$ relationship for decades "since quit date". There was a strong signal for current 
cigarette smoking per se and the dose-response association for increasing smoking intensity was less pronounced with only minimal decline seen for those with a remote smoking history. These observations are consistent with the Copenhagen City Health Study (CCHS) that found a strong relationship between continued smoking and development of COPD [OR 6.3 (95\% CI: 4.2-9.5)], and also a decreasing relationship with longer time periods since quitting smoking (22). Thus, a modified version of the original Fletcher and Peto diagram is presented [see Figure 1 (10)].

From longitudinal studies such as the CCHS, at least $25 \%$ of current cigarette smokers are at risk of developing the lung function feature of COPD (22). For such long-term cohorts, this estimate may be higher due to the phenomena of survivor bias and the healthy smoker effect (9). Given the median birth age for the NHLBI Pooled Cohorts Study was in the 1930s before the widespread influence of population-based public health strategies, individuals who developed symptoms may have quit smoking prior to major airway changes (9). Thus, the group quitting more than 30 years ago may represent a group of predominately susceptible smokers who stopped early due to respiratory symptomatology.

The authors make the distinction between normalization and ongoing subtle deterioration of $\mathrm{FEV}_{1}$ decline, the latter suggesting the possibility of ongoing active lung damage following smoking cessation that might be amenable to additional preventive strategies. While cross-sectional histopathological findings support the widely held view that airway inflammation and remodelling persists after smoking cessation $(15,16)$, the present study does not identify these susceptible individuals (23). Nor does the study address other causes of impaired lung function such as the interaction of smoking with asthma resulting in asthma-COPD overlap $(13,24)$, nor effects of air pollution and occupational hazards. It is also difficult to interpret the $\mathrm{FEV}_{1}$ values for an individual given that actual lung function varies widely with age, sex, height and ethnicity. To place the presented $\mathrm{FEV}_{1}$ values in some context, 3.8-4.1 litres (around 4,000 $\mathrm{mL}$ ) approximates the predicted $\mathrm{FEV}_{1}$ of a $40-45$ year old Caucasian male measuring $172-180 \mathrm{~cm}$ in height, whereas the study reports an average lung function loss for a current smoker to be $40 \mathrm{~mL} / \mathrm{year}$ with an excess of 8-10 mL/year beyond 'normal' ageingsusceptible smokers may lose up to $60-90 \mathrm{~mL} / \mathrm{yr}$. However, for susceptible ex-smokers with a shorter and/or more remote smoking history, the excess in $\mathrm{FEV}_{1}$ decline is much less likely to manifest as clinical COPD in the absence of other major risk factors across the life-course.

Finally, the authors conclude that the lung function findings reinforce the recommendation that 'no level of tobacco smoke exposure is safe' and smoking cessation is key to maintaining maximal lung function. The doseresponse associations indirectly confirm the dogma that 'the time to stop smoking is now' which is fundamental to COPD prevention in the general population. Although the decline in smoking from population-based strategies in many high-income countries has been a public health triumph, more evidence is needed to support a more targeted approach directed towards susceptible individuals in terms of active case finding and personalised interventions using modern technologies. However, for a country like China which has high and sustained smoking rates for men, an escalation of effective public health policy across the general population is more urgently needed to reduce tobacco consumption and cardiorespiratory morbidity and mortality in the future (25).

\section{Acknowledgments}

Funding: None.

\section{Footnote}

Provenance and Peer Review: This article was commissioned by the editorial office, Annals of Translational Medicine. The article did not undergo external peer review.

Conflicts of Interest: Both authors have completed the ICMJE uniform disclosure form (available at http://dx.doi. org/10.21037/atm-20-3667). JLP has received a travel grant from Boehringer-Ingelheim. The other author has no conflicts of interest to declare.

Ethical Statement: The authors are accountable for all aspects of the work in ensuring that questions related to the accuracy or integrity of any part of the work are appropriately investigated and resolved.

Open Access Statement: This is an Open Access article distributed in accordance with the Creative Commons Attribution-NonCommercial-NoDerivs 4.0 International License (CC BY-NC-ND 4.0), which permits the noncommercial replication and distribution of the article with the strict proviso that no changes or edits are made and the 
original work is properly cited (including links to both the formal publication through the relevant DOI and the license). See: https://creativecommons.org/licenses/by-nc-nd/4.0/.

\section{References}

1. U.S. Department of Health and Human Services. The health consequences of smoking - 50 years of progress. Atlanta, GA: Department of Health and Human Services; 2014.

2. Wang TW, Asman K, Gentzke AS, et al. Tobacco Product Use Among Adults - United States, 2017. MMWR Morb Mortal Wkly Rep 2018;67:1225-32.

3. Poulos LM, Cooper SJ, Ampon R, et al. Mortality from asthma and COPD in Australia. Australian Institute of Health and Welfare (AIHW). Cat. no. ACM 30. Canberra: AIHW. Available online: https://www.aihw.gov.au/reports/ chronic-respiratory-conditions/copd/contents/deaths Accessed 04-02-20; 2014.

4. Wen H, Xie C, Wang L, et al. Difference in Long-Term Trends in COPD Mortality between China and the U.S., 1992(-)2017: An Age(-)Period(-)Cohort Analysis. Int J Environ Res Public Health 2019;16:1529.

5. Yang G, Fan L, Tan J, et al. Smoking in China: findings of the 1996 National Prevalence Survey. JAMA 1999;282:1247-53.

6. Fang L, Gao P, Bao H, et al. Chronic obstructive pulmonary disease in China: a nationwide prevalence study. Lancet Respir Med 2018;6:421-30.

7. Dong GH. Ambient air pollution in China. Respirology 2019;24:626-7.

8. WHO Report on the Global Tobacco Epidemic, 2019. Geneva: World Health Organization; 2019. Licence: CC BY-NC-SA 3.0 IGO.

9. Fletcher C, Peto R. The natural history of chronic airflow obstruction. Br Med J 1977;1:1645-8.

10. Boston University School of Public Health. Available online: http://sphweb.bumc.bu.edu/otlt/MPH-Modules/ PH/RespiratoryHealth/RespiratoryHealth5.html Accessed 22-04-20.

11. Oelsner EC, Balte PP, Bhatt SP, et al. Lung function decline in former smokers and low-intensity current smokers: a secondary data analysis of the NHLBI Pooled

Cite this article as: Perret JL, Walters EH. Cigarette smoking and lung function decline beyond quitting. Ann Transl Med 2020;8(22):1531. doi: 10.21037/atm-20-3667
Cohorts Study. Lancet Respir Med 2020;8:34-44.

12. Anthonisen NR, Connett JE, Kiley JP, et al. Effects of smoking intervention and the use of an inhaled anticholinergic bronchodilator on the rate of decline of FEV1. The Lung Health Study. JAMA 1994;272:1497-505.

13. Global Initiative for Asthma. Global Initiative for Chronic Obstructive Lung Disease. Diagnosis of Diseases of Chronic Airflow Limitation. Asthma COPD and AsthmaCOPD Overlap Syndrome (ACOS). 2014.

14. Anthonisen NR, Connett JE, Murray RP. Smoking and lung function of Lung Health Study participants after 11 years. Am J Respir Crit Care Med 2002;166:675-9.

15. Hogg JC, Chu F, Utokaparch S, et al. The nature of smallairway obstruction in chronic obstructive pulmonary disease. N Engl J Med 2004;350:2645-53.

16. Eapen MS, McAlinden K, Tan D, et al. Profiling cellular and inflammatory changes in the airway wall of mild to moderate COPD. Respirology 2017;22:1125-32.

17. Lee PN, Fry JS. Systematic review of the evidence relating FEV1 decline to giving up smoking. BMC Med 2010;8:84.

18. Oelsner EC, Balte PP, Cassano PA, et al. Harmonization of Respiratory Data From 9 US Population-Based Cohorts: The NHLBI Pooled Cohorts Study. Am J Epidemiol 2018;187:2265-78.

19. Donohue JF. Minimal clinically important differences in COPD lung function. COPD 2005;2:111-24.

20. Chen Y, Chen H, Li Z. Effect of characteristics and life in cities in China on residents' smoking behaviour. J Int Med Res 2018;46:4226-34.

21. Zhang S, Wei Z, Liu W, et al. Indicators for Environment Health Risk Assessment in the Jiangsu Province of China. Int J Environ Res Public Health 2015;12:11012-24.

22. Lokke A, Lange P, Scharling H, et al. Developing COPD: a 25 year follow up study of the general population. Thorax 2006;61:935-9.

23. Colak Y, Lange P. The long-lasting dark shadow of past and present smoking. Lancet Respir Med 2020;8:3-5.

24. Perret JL, Dharmage SC, Matheson MC, et al. The Interplay between the Effects of Lifetime Asthma, Smoking, and Atopy on Fixed Airflow Obstruction in Middle Age. Am J Respir Crit Care Med 2013;187:42-8.

25. Sun Y, Sin DD. Crisis of COPD in China: the future is now. Lancet Respir Med 2018;6:404-5. 